\section{The evidence informing the surgeon's selection of intraocular lens on the basis of light transmittance properties}

$X \mathrm{Li}^{1}, \mathrm{D}$ Kelly ${ }^{2}, \mathrm{JM}$ Nolan${ }^{2}, \mathrm{JL}$ Dennison ${ }^{2}$

and S Beatty ${ }^{2,3}$
${ }^{1}$ Pharmaceutical \& Molecular Biotechnology Research Centre, Department of Chemical \& Life Sciences, Waterford Institute of Technology, Waterford, Ireland

${ }^{2}$ Nutrition Research Centre Ireland, Macular Pigment Research Group, School of Health Science, Waterford Institute of Technology, Waterford, Ireland

${ }^{3}$ Institute of Vision Research, Whitfield Clinic, Waterford, Ireland

Correspondence:

$X$ Li, Pharmaceutical \& Molecular Biotechnology Research Centre,

Department of Chemical \& Life Sciences, Waterford Institute of Technology, Macular Pigment Research Group, Carriganore House, W.I.T. West Campus, Carriganore, Waterford, Ireland

Tel: +353 5130 6261;

Fax: +35351834046.

E-mail: xue215@gmail.com

Received: 24 June 2016 Accepted in revised form: 27 September 2016

Published online:

9 December 2016

\begin{abstract}
In recent years, manufacturers and distributors have promoted commercially available intraocular lenses (IOLs) with transmittance properties that filter visible short-wavelength (blue) light on the basis of a putative photoprotective effect. Systematic literature review. Out of 21 studies reporting on outcomes following implantation of blue-light-filtering IOLs (involving 8914 patients and 12919 study eyes undergoing cataract surgery), the primary outcome was vision, sleep pattern, and photoprotection in $9(42.9 \%), 9(42.9 \%)$, and $3(14.2 \%)$ respectively, and, of these, only $7(33.3 \%)$ can be classed as high as level $\mathbf{2 b}$ (individual cohort study/low-quality randomized controlled trials), all other studies being classed as level $3 \mathrm{~b}$ or lower. Of the level $2 \mathrm{~b}$ studies, only one $(\mathbf{1 4 . 3 \% )}$ found in favor of blue-light-filtering IOLs $v s$ ultraviolet (UV)-only filtering IOLs on the basis of an association between better post-operative contrast sensitivity (CS) at select frequencies with the former; however, that study did not measure or report CS preoperatively in either group, and the finding may simply reflect better preoperative CS in the eyes scheduled to be implanted with the blue-light-filtering IOL; moreover, that study failed to measure macular pigment, a natural preceptoral filter of bluelight, augmentation of which is now known to improve CS. In terms of photoprotection, there is no level $2 \mathrm{~b}$ (or higher) evidence in support of blue filtering IOLs vs UV-only filtering IOLs. On the basis of currently available evidence, one cannot advocate for the use of blue-lightfiltering IOLs over UV-only filtering IOLs. Eye (2017) 31, 258-272; doi:10.1038/eye.2016.266; published online 9 December 2016
\end{abstract}

\section{Introduction}

Cataract surgery and intraocular lens (IOL) implantation is the most commonly performed surgical procedure worldwide, ${ }^{1}$ and the need for such surgery is likely to rise because of increasing longevity. ${ }^{2}$ Commercially available IOLs can vary in terms of material (polymethylmethacrylate, polymers, silicone or acrylic), ${ }^{3,4}$ hydrophobicity (hydrophobic $v s$ hydrophilic), ${ }^{5}$ sphericity (aspheric vs spheric) ${ }^{6}$ and light-filtering properties. In this paper, we review the evidence germane to the putative and relative risks and/or benefits of implanting IOLs that filter visible shortwavelength light (ie, $<500 \mathrm{~nm}$ ), referred to as blue-light-filtering IOLs for the purpose of this review.

In this article, we grade each study according to the quality of evidence it represents, on the basis of the Oxford (UK) Centre for EvidenceBased Medicine (CEBM) criteria, described below:

1a. Systematic review (homogeneous) of randomized controlled trials (RCT) with narrow confidence intervals: RCTs are studies where the participants are randomly allocated to one or other of the different interventions under investigations, and the greater the sample size, the reduced likelihood of bias;

1 b. Individual RCT with narrow confidence interval.

2a. Systematic review of (homogeneous) cohort studies.

2b. Individual cohort study/low-quality RCT.

3a. Systematic review of (homogeneous) case-control studies.

3b. Individual case-control studies.

4. Case series, low-quality cohort, or casecontrol studies.

5. Expert opinions without explicit critical appraisal, or based on physiology, bench research or first principles. 


\section{The visible and near-visible spectrum}

The visible and near-visible spectrum represents a small proportion of the total electromagnetic spectrum, and comprises wavelengths $(\lambda)$ ranging from 200 to $780 \mathrm{~nm}$. This includes ultraviolet (UV) radiation, visible light (400$780 \mathrm{~nm}$ ), and some short-wavelength infrared radiation. 7,8 The cornea, vitreous, and aqueous transmit wavelengths $>300 \mathrm{~nm}$, and it rests on the crystalline lens to absorb UV radiation, which it does in an age-dependent manner (ie, optical lens absorption increases with age). ${ }^{9-11}$

\section{Vision and the visible spectrum}

Vision depends on photoreceptive cells adapted to the lighting conditions, and may be classed as photopic (vision under well-lit conditions; mediated by short-wavelength [S], middle-wavelength [M], and long-wavelength [L] cones; maximum efficacy at $683 \mathrm{~lm} / \mathrm{W}$ at $555 \mathrm{~nm}$; luminance levels of 10 to $10^{6} \mathrm{~cd} / \mathrm{m}^{2}$ ), scotopic (vision under very poorly-lit conditions; mediated exclusively by spectrally insensitive rods; luminance levels of $10^{-2}-10^{-6} \mathrm{~cd} / \mathrm{m}^{2}$ ) and mesopic (under low, but not quite dark, lighting conditions; mediated by rods and cones; luminance levels of $\left.10^{-2}-10 \mathrm{~cd} / \mathrm{m}^{2}\right) .{ }^{12}$ Of note, the terms 'scotopic' and 'mesopic' are not interchangeable, as rods contribute solely to scotopic vision whereas mesopic vision is subserved by rods and cones.

The impact of dark adaptation, that is, switching from cones to rods to process light, is known as the Purkinje shift, and results in a shift of the peak luminance sensitivity of the human eye from the red end toward the blue end of the spectrum at low illumination levels, ${ }^{12}$ such that blue light is responsible for $35 \%$ of aphakic scotopic vision compared with only $7 \%$ of photopic vision. ${ }^{13,14}$

\section{Central vision}

Central vision is mediated by the central macula, a region of the retina $\sim 3 \mathrm{~mm}$ in diameter centered at the fovea centralis (positioned at $0^{\circ}$ eccentricity) and slightly larger than the region that contains the macular carotenoids (4-6 $6^{\circ}$ in diameter). ${ }^{15}$ To subserve its function in terms of fine detail vision, the macula is dominated by cones, which are stimulated by high-intensity light. The three types of cones (S-, M-, and L-) each contain different opsins that alter the spectral absorption properties of the photopigments, each therefore preferentially responding to short-, middle-, and long-wavelength visible light, respectively. ${ }^{16}$ The red/green $(\mathrm{R} / \mathrm{G})$ color system is served by the L- and M-cones, whereas the blue/yellow $(\mathrm{B} / \mathrm{Y})$ color system is served by the S-cones and a combination of the L- and M-cones. ${ }^{17,18}$ Studies have shown good evidence that the B/Y channel has adaptation mechanisms to compensate for shortwavelength light loss (due to macular pigment (MP) and the crystalline lens), whereas this is not the case with the $\mathrm{R} / \mathrm{G}$ channel and has not been shown for rods. ${ }^{19,20}$

\section{Visible short-wavelength light}

For the purpose of this review, visible short-wavelength light refers to wavelengths between 400 and $500 \mathrm{~nm}$, and includes violet (400-440 nm) and blue (440-500 nm ). ${ }^{14}$

\section{Visible short-wavelength light and central vision}

Blue light and chromatic aberration Short-wavelength light is deleterious to image formation at the central fovea because of the consequences of chromatic aberration (CA) and light scatter. CA (specifically longitudinal CA) refers to the wavelength-dependence of the refractive power of the eye, whereby (in an emmetropic state) green wavelengths (520-570 nm) are focused at the foveal plane, but blue light is myopically defocused by $\sim 1.2$ diopters, resulting in a blurred image. ${ }^{21}$ Transverse CA results from oblique incident light waves being focused in the same focal plane, but not along the optical axis, thus resulting in a blue haze surrounding the object being viewed. ${ }^{22,23}$ CA adversely affects the ability to discern the foreground from the background within the field of view (known as contrast sensitivity, or CS), ${ }^{24-26}$ although there is some evidence to suggest that the eye's optical imperfections go some way to attenuating the effects of longitudinal CA. ${ }^{27}$

Blue light and light scatter Light scatter, which occurs both internal and external to the eye, is responsible for veiling luminance and glare disability.

Straylight is the consequence of intraocular light scatter, and is classed as forward scatter (by the cornea and lens, each of these structures contributing to $\sim 30 \%$ of intraocular light scatter within the young, healthy, Caucasian eye) and sideward scatter (by the fundus, accounting for $\sim 40 \%$ of intraocular light scatter, and which decreases with increasing eccentricity, such that such sideward scatter in the peripheral retina is only half that occurring at the fovea). ${ }^{28,29}$ The wavelengthdependence of intraocular light scatter remains a matter of debate, with some studies suggesting that visible shortwavelength (blue) light is subject to a greater degree of intraocular light scatter than are longer visible wavelengths. ${ }^{9,30,31}$

External to the eye, light waves are reflected and diffracted by a variety of particles suspended in the atmosphere, and such particles include oxygen and nitrogen, haze aerosols, fog, mist, clouds, amongst others. When light is incident on particles smaller than the 
wavelength of light, Rayleigh (ie, non-directional) scattering occurs, where the degree of scattering is proportionate to the inverse fourth power of the wavelength. Therefore, short-wavelength blue light is scattered much more than light of longer wavelengths. ${ }^{32}$ When particle size is greater than $\sim 0.1 \lambda$, Mie scattering occurs. ${ }^{33}$ In Mie scattering, particles randomly reflect the waves of light. Both Rayleigh and Mie scattering contribute to veiling luminance, the former being more important and wavelength-dependent, rendering the scatter of blue visible light the predominant cause of veiling luminance and glare disability. ${ }^{32,34}$

The consequences of veiling luminance are best illustrated by the experience of someone attending a barbecue on a sunny, summer afternoon, when the embers of the coal appear gray, and cannot be discerned one from the other. Several hours later, at twilight, and when there is little visible light (and therefore inconsequential light scatter), the embers are clearly discernible in spite of unchanged luminances of the embers. This occurs because the just-noticeabledifferences for discriminability of objects of differing luminance are increased in the presence of visible light scattered across the retina (veiling luminance). ${ }^{32,35}$ Of note, the adverse impact of veiling luminance is compounded in the presence of environmental light that is too intense or variable across the visual field (a phenomenon known as glare disability), reflected in the visual experience of someone on a sailing boat on a bright summer's day. ${ }^{36,37}$ Importantly, under such conditions, loss of CS is greater in dim than in bright light environments (eg, strong oncoming headlights whilst driving at night) because rods need greater contrast differences for target detection than do cones ( 20 vs 1\%, respectively). ${ }^{36}$

Finally, it should be borne in mind that the central fovea does not contain S-cones, and therefore blue visible light cannot contribute to high-frequency spatial vision. ${ }^{38,39}$

\section{Light-filtering properties and visual consequences of macular pigment}

Preceptoral filtration of short-wavelength visible light at the fovea is important for optimal central vision, and this is achieved naturally by the selective accumulation of three carotenoids (lutein [L], zeaxanthin [Z], and mesozeaxanthin [MZ]) at this tissue, collectively referred to as MP. ${ }^{34}$ The absorbance spectrum of MP peaks at $460 \mathrm{~nm}$ (blue visible light), and an average amount of MP (0.40 optical density units) filters out $\sim 40 \%$ of blue light incident on the macula (Figure 1). ${ }^{40,41}$ Wooten and Hammond reported that transmission of visible shortwavelength (blue) light decreases substantially with increasing MP optical density (MPOD), so that 0.10 MPOD units would transmit $\sim 80 \%$ of light at $460 \mathrm{~nm}$, 0.50 MPOD units would transmit $\sim 33 \%$ of light at $460 \mathrm{~nm}$, and $1.00 \mathrm{MPOD}$ units would transmit $\sim 10 \%$ of light at $460 \mathrm{~nm}$ (Figure 2). ${ }^{32}$

Accordingly, the investigators hypothesized that the resulting decrease in luminance of this short-wavelength light due to MP absorbance would improve contrast between a background (consisting of blue haze) and a target, thereby increasing visual range and improving discernibility of a target's low-contrast internal details in a way that is proportionate to MPOD. In practical terms, therefore, an average amount of MP (0.5 OD) would

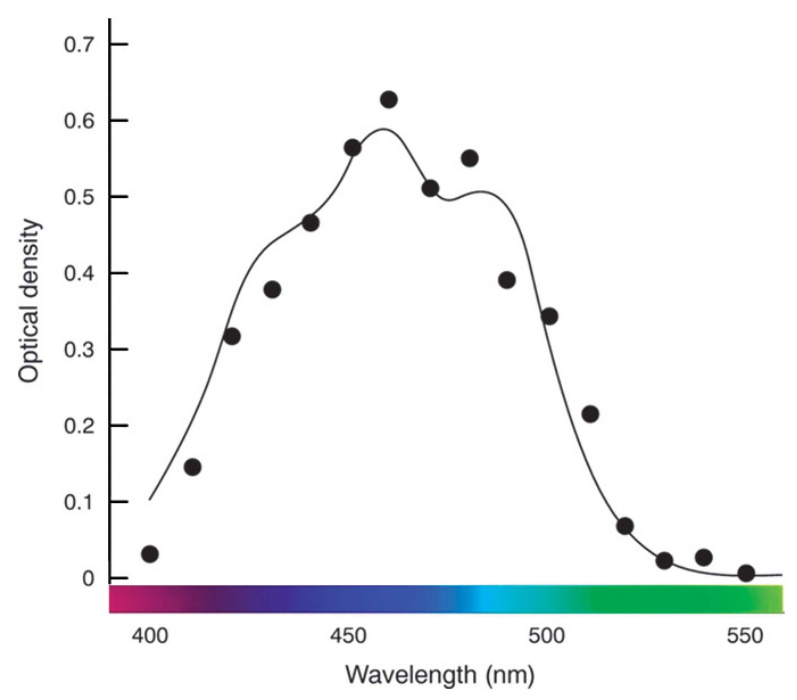

Figure 1 The absorbance spectrum of MP peaks at $460 \mathrm{~nm}$. An average amount of MP (0.40 optical density units) filters out $\sim 40 \%$ of blue light incident on the macula. ${ }^{40,41}$

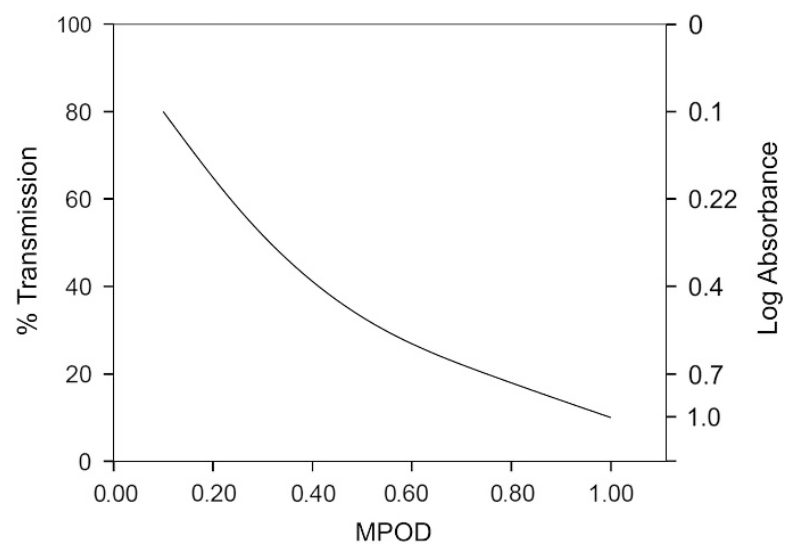

Figure 2 The percent transmission and log absorbance of $460 \mathrm{~nm}$ light by MP, with respect to MPOD. Transmission of visible short-wavelength (blue) light decreases substantially with increasing MPOD. ${ }^{32}$ 
increase visual range by $18.6 \%$, whereas a high level of MP (1.0 OD) would increase visual range by $30 \%$.

Equally, and in terms of CS, a target that is discriminated $50 \%$ of the time in the absence of MP $(0.0 \mathrm{OD})$ is discerned $88 \%$ of the time in the presence of an average amount of MP (0.5 OD) and almost $100 \%$ of the time for a high amount of MP (1.0 OD). ${ }^{32}$ Indeed, the visual benefits of $\mathrm{MP}$ are consistent with the results of clinical trials in diseased $^{42-45}$ and non-diseased eyes. ${ }^{34,46-55}$

\section{Light-filtering properties of the non-cataractous crystalline lens}

The crystalline lens blocks UV radiation between 300 and $400 \mathrm{~nm}$, up to $390 \mathrm{~nm}$ in a young eye and up to $400 \mathrm{~nm}$ in a 63-year-old lens. ${ }^{9,56}$ The human lens grows throughout an individual's lifespan by a process of epithelial cell division, yet none of its cells are cast off. Such terminal differentiation within a closed avascular system necessitates continuous remodelling to achieve such growth and maintain light transmission. ${ }^{11}$ However, the cumulative insults of radiation, oxidation, and posttranslational modification result in an age-related increase in light scatter, fluorescence, and spectral absorption, especially at the short-wavelength end of the visible spectrum. The greatest increase in absorption is for wavelengths $\sim 460-470 \mathrm{~nm}$ (blue light), and this is largely attributable to post-natal accumulation of chromophores. ${ }^{57}$

\section{Light-filtering properties of the cataractous crystalline lens}

The aging, yellowing, and opacified crystalline lens is only one-third as translucent to visible short-wavelength light when compared with the youthful lens. For example, a 53-year-old and a 75-year-old crystalline lens transmit 70 and $25 \%$ of incident visible blue light, respectively. ${ }^{58}$

\section{Light-filtering properties of UV-only filtering IOLs}

Initially, IOLs were manufactured from polymethylmethacrylate and did not include UVRblocking chromophores. ${ }^{59}$ Retinophototoxicity attributable to UVR transmission was recognized in $1978,{ }^{59,60}$ such that most IOLs contained UVR-absorbing chromophores by $1980 .^{61}$

\section{Visible light-filtering IOLs}

A standard UV-only filtering IOL typically absorbs wavelengths up to $420 \mathrm{~nm}$. In contrast, blue light-filtering IOLs contain chromophores that block wavelengths between 400 and $500 \mathrm{~nm}$, and are typically classed as blue-blockers (absorbing visible light in the blue part of the spectrum, circa $450-500 \mathrm{~nm}$ ) and violet-blockers (absorbing only the violet part of the spectrum, circa 410-440 nm, but transmitting blue light). For example, the Alcon AcrySof Natural IOL reduces transmittance of short-wavelength light by $94 \%$ (1.22 log units of absorbance) at $400 \mathrm{~nm}, 53 \%$ (0.33 log units of absorbance) at $450 \mathrm{~nm}$, and $31 \%$ (0.16 log units of absorbance) at $475 \mathrm{~nm}$, and is therefore considered a blue light-filtering IOL. ${ }^{62}$ The Bausch + Lomb SofPort AO with Violet Shield Technology reduces short-wavelength light transmission by $99.5 \%$ (2.3 log units of absorbance) at $400 \mathrm{~nm}, 36.8 \%$ (0.2 log units of absorbance) at $425 \mathrm{~nm}, 11.2 \%$ (0.05 log units of absorbance) at $450 \mathrm{~nm}$, and 9.2\% (0.04 log units of absorbance) at $475 \mathrm{~nm}$, and is therefore considered a violet blocker ${ }^{7}$ (Figure 3).

\section{The rationale and evidence base upon which implantation of blue-light-filtering iols is premised}

\section{Blue-light-filtering IOLs and central vision}

A patient-masked, randomized, crossover study (evidence level 2b, Table 1), involving 154 bilaterally pseudophakic patients (having been implanted with UVonly filtering IOLs) were recruited to investigate whether filtration of visible short-wavelength blue light impacted on visual performance and experience under conditions of intense light $\left(0.1\right.$ candela $\left./ \mathrm{m}^{2}\right) .{ }^{63}$ Outcome measures included photostress recovery time and glare disability thresholds, under conditions of wearing clip-on blue light-filtering spectacles vs wearing clip-on UV-only filtering spectacles. In brief, the use of a clip-on blue-lightfiltering lens on pseudophakic patients increased their ability to tolerate glare and enhanced their recovery following photostress. However, it should be noted that

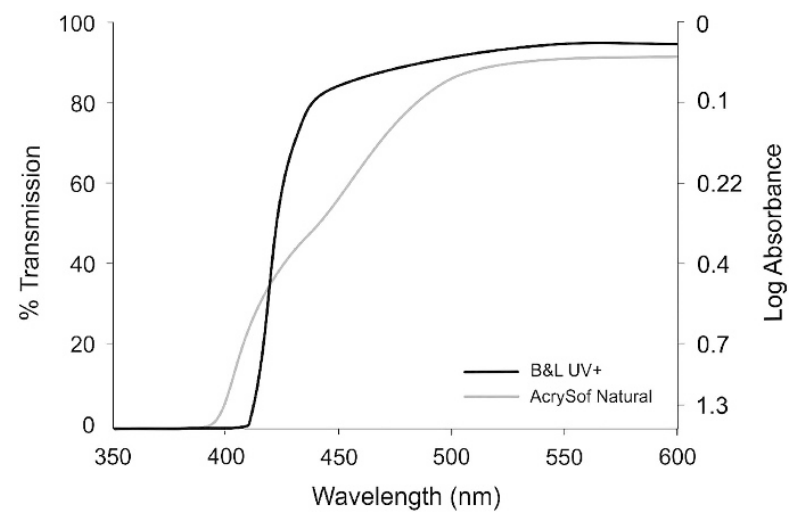

Figure 3 Comparison of the different transmission properties of Alcon AcyrSof Natural (blue light-filtering IOLs) and Bausch + Lomb SofPort AO with Violet Shield Technology (UV-only filtering IOLs). ${ }^{7}$ 


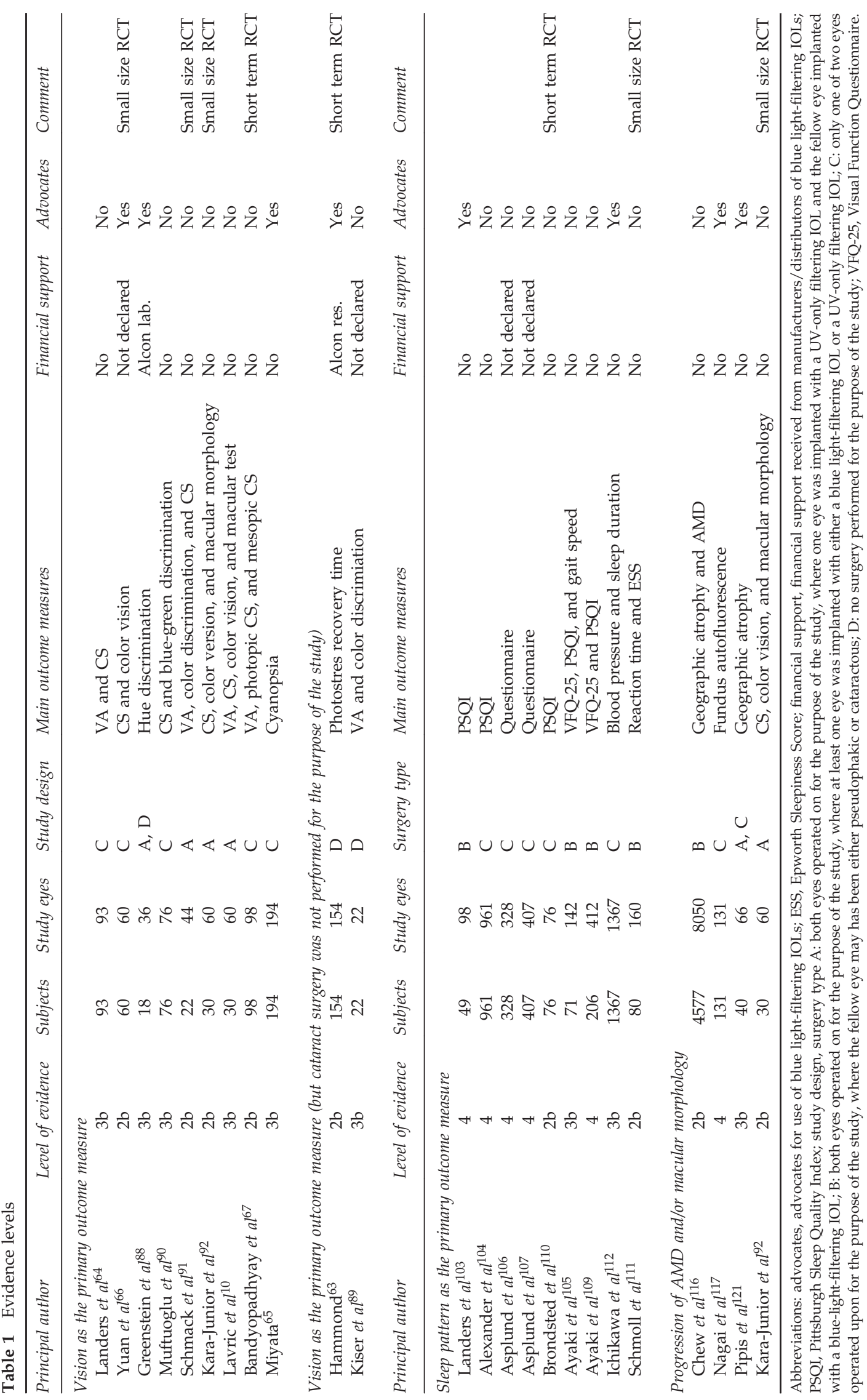


these results can only give an indication as to whether there is a difference between the use of blue light-filtering clip-on lenses vs UV-only filtering clip-on lenses on already pseudophakic eyes and, even then, only under conditions of intense light.

A non-randomized, controlled trial of Alcon AcrySof Natural IOLs (blue light-filtering IOLs) vs Alcon AcrySof single piece IOLs (UV-only filtering IOLs), representing level $3 \mathrm{~b}$ evidence and including one eye (the study eye) of 93 patients in whom the fellow eye was already pseudophakic with a UV-only filtering IOL, revealed no difference between the two IOL types in terms of visual acuity (VA), CS or color perception. ${ }^{64}$

In a comparative, single center, non-randomized study (evidence level 3b, Table 1), 60 eyes of 30 patients were implanted with either a UV-only filtering IOL (AcrySof SA60AT) in one eye or a blue light-filtering IOL (AcrySof SN60WF) in the fellow eye. ${ }^{10}$ Two years following surgery, VA, color vision, CS, macular thickness, and macular volume were compared, and there were no significant differences between fellow eyes in terms of any of these outcome measures. ${ }^{10}$

A retrospective study (evidence level $3 b$, Table 1) designed to compare the prevalence of cyanopsia (seeing everything tinged with blue) in eyes implanted with either a UV-only filtering IOL or a blue light-filtering IOL, 65 where cyanopsia was graded on the basis of white gradation cards (in a system known as the neutralization method), has been reported. The study comprised one eye of patients implanted with a UV-only filtering IOL (Acrysof SA60AT; $n=57$ ), known as Group 1, and one eye (of different patients) implanted with the blue lightfiltering IOL (Hoya AF-1 YA60BB; $n=96$ ), known as Group 2, and a further reference group $(n=41)$ comprising healthy patients without either cataract or prior cataract surgery. ${ }^{65}$ Although cyanopsia did occur more frequently in Group 1 than in Group 2 one month postoperatively (14.5 vs $4.9 \% ; P=0.049$ ), this difference was no longer significant 3 months following surgery (9.1 vs $5.2 \% ; P>0.05)$.

One small randomized study (evidence level $2 b$, Table 1) demonstrated superior CS postoperatively in association with use of blue light-filtering IOLs vs UVonly filtering IOLs. ${ }^{66}$ Sixty patients scheduled for cataract surgery were randomly assigned to receive either a blue light-filtering IOL (model not specified; $n=30$ ) or a UVonly filtering IOL (model not specified; $n=30$ ) in one eye, where the fellow eye was cataractous. VA, CS, and color vision were examined up to 6 months postoperatively, when no significant difference in VA or color vision between eyes implanted with a UV-only filtering IOL vs a blue light-filtering IOL was observed, although superior CS at select spatial frequencies was noted among eyes implanted with a blue light-filtering IOL one week postoperatively $(1.5 \mathrm{c} / \mathrm{d}, P=0.0076 ; 3 \mathrm{c} / \mathrm{d}, P=0.0142$; and $6 \mathrm{c} / \mathrm{d}, P=0.0269), 1$ month postoperatively $(1.5 \mathrm{c} / \mathrm{d}$, $P=0.0067 ; 3 \mathrm{c} / \mathrm{d}, P=0.0088$; and $6 \mathrm{c} / \mathrm{d}, P=0.0098)$, 3 months postoperatively $(1.5 \mathrm{c} / \mathrm{d}, P=0.0047 ; 3 \mathrm{c} / \mathrm{d}$, $P=0.0051$; and $6 \mathrm{c} / \mathrm{d}, P=0.0033)$, and 6 months postoperativerly $(1.5 \mathrm{c} / \mathrm{d}, P=0.0058 ; 3 \mathrm{c} / \mathrm{d}, P=0.0046$; and $6 \mathrm{c} / \mathrm{d}, P=0.0026) .{ }^{66}$ However, this study is fundamentally flawed as the authors did not measure or report preoperative measures of CS in either group, and post-operative disparity between the two IOL groups may simply reflect preoperatively disparity between the two groups in this respect. Other obvious shortcomings in this study include: cataract operations were performed by extracapsular cataract surgery; the failure to specify the models of IOLs implanted; the failure to measure and control for MP (the augmentation of which is now known to enhance CS in diseased ${ }^{42-45}$ and non-diseased eyes $\left.^{34,46-49,51-53}\right)$. Accordingly, it is doubtful whether this study should, in fact, be classed as level $2 b$.

\section{Blue-light-filtering IOLs and photopic vision}

In one study (evidence level $2 b$, Table 1 ), one eye of 98 patients was randomly implanted with either a UV-only filtering IOL (AcrySof SA60AT) or a blue light-filtering IOL (AcrySof SN60AT with IMPRUV filter). ${ }^{67}$ One month following surgery, CS was measured under photopic and mesopic conditions in the study eye, and it was observed that eyes implanted with blue light-filtering IOLs were comparable to those implanted with UV-only filtering IOLs in terms of the outcome measures (VA, photopic CS and mesopic CS). An obvious shortcoming of this study rests on the minuscule duration of follow-up for the intended purpose.

Importantly, it should be reiterated that none of the studies comparing central cone-mediated, visual function following implantation of blue light-filtering IOLs vs UVonly filtering IOLs have measured (or corrected for) MP, the inter-individual variability of which is substantial, $, 54,68$ and are therefore only in a position to comment on the impact of a blue-light filter (the blue light-filtering IOL) superimposed on another (but unmeasured) blue-light filter (ie, MP). $58,64,66$

\section{Blue-light-filtering IOLs and mesopic/scotopic central and peripheral vision}

For an eye adapted to dim illumination, scotopic sensitivity peaks at $505 \mathrm{~nm}$ in the blue-green part of the spectrum, and cannot detect wavelengths greater than about $640 \mathrm{~nm} \cdot{ }^{12,40}$ The Commission Internationale de l'Eclairage (CIE) standard spectral luminance efficiency function for scotopic vision, known as $\mathrm{V}_{\lambda}^{\prime}$, and illustrated in Figure 4, is dependent on short-wavelength visible 
(blue) light and is similar to the absorption spectrum for rhodopsin (which peaks at $500 \mathrm{~nm}$ ). ${ }^{69,70}$ Indeed, that observation represented the key reason for concluding that rhodopsin, which is only contained in rods, mediates scotopic vision. ${ }^{71,72}$

There are $~ 91$ million rod photoreceptors and 4.5 million cone photoreceptors in the human retina. ${ }^{73}$ There are no rods contained in the central $1.25^{\circ}$ of the

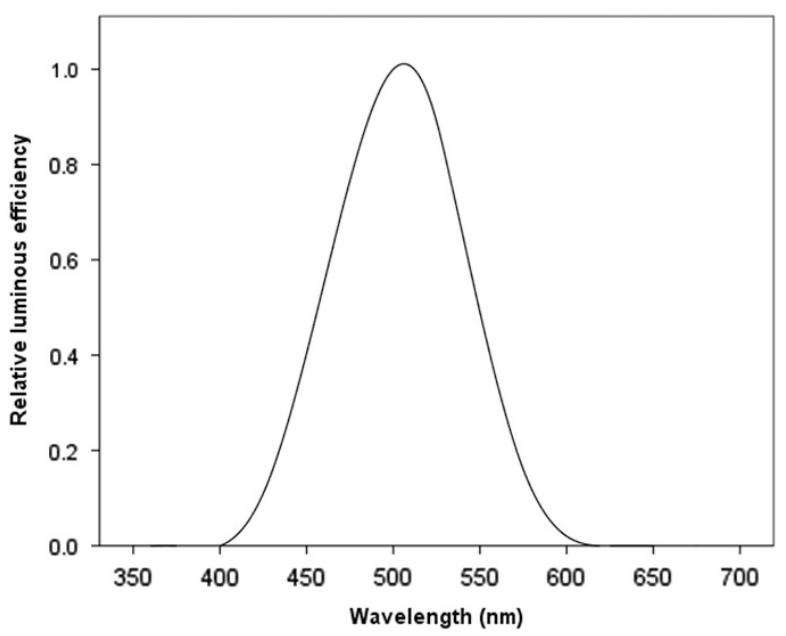

Figure 4 The relative spectral luminous scotopic efficiency of the CIE standard photometric observer $\left(\mathrm{V}^{\prime}{ }_{\lambda}\right)$ depends on shortwavelength visible (blue) light and peaks at $507 \mathrm{~nm}^{69,70}$ fovea, ${ }^{74}$ whereas cone density peaks at this location (100 000-324 000 cones $/ \mathrm{mm}^{2}$, but subject to considerable inter-individual variability) and declines to 5000 cones/ $\mathrm{mm}^{2}$ or less in peripheral retina ${ }^{39,75}$ (Figure 5).

Photopic and scotopic sensitivity decline with increasing age. However, the rate of age-related decline in scotopic vision is twice as fast as that of photopic vision, and results in the observed difficulties that older adults experience in dim environments. ${ }^{76}$ The reason for the faster age-related decline in scotopic vision is probably related to the observation that aging has little effect on the number of human foveal cone photoreceptors, whereas parafoveal rod photoreceptors decline in number by $30 \%$ with increasing age. ${ }^{77,78}$

Specifically, scotopic CS declines at low and high spatial frequencies, ${ }^{79}$ and rod-mediated dark adaptation slows progressively with increasing age ${ }^{80}$ Further, the age-related loss of scotopic sensitivity is most severe for visible short-wavelength (blue) light. ${ }^{81}$ These age-related changes in scotopic visual function contribute to an increased risk of falling, ${ }^{82}$ and the need to be closer to road signs to read them effectively at night, ${ }^{83}$ amongst older adults.

The Purkinje shift, characterized by the differing peaks of spectral sensitivity for scotopic $(507 \mathrm{~nm})$ and photopic (555 nm) vision, results in blue light being responsible for $7 \%$ of photopic vision but for $35 \%$ of aphakic scotopic vision. ${ }^{13,14}$ As blue light-filtering IOLs filter out $27-40 \%$ of

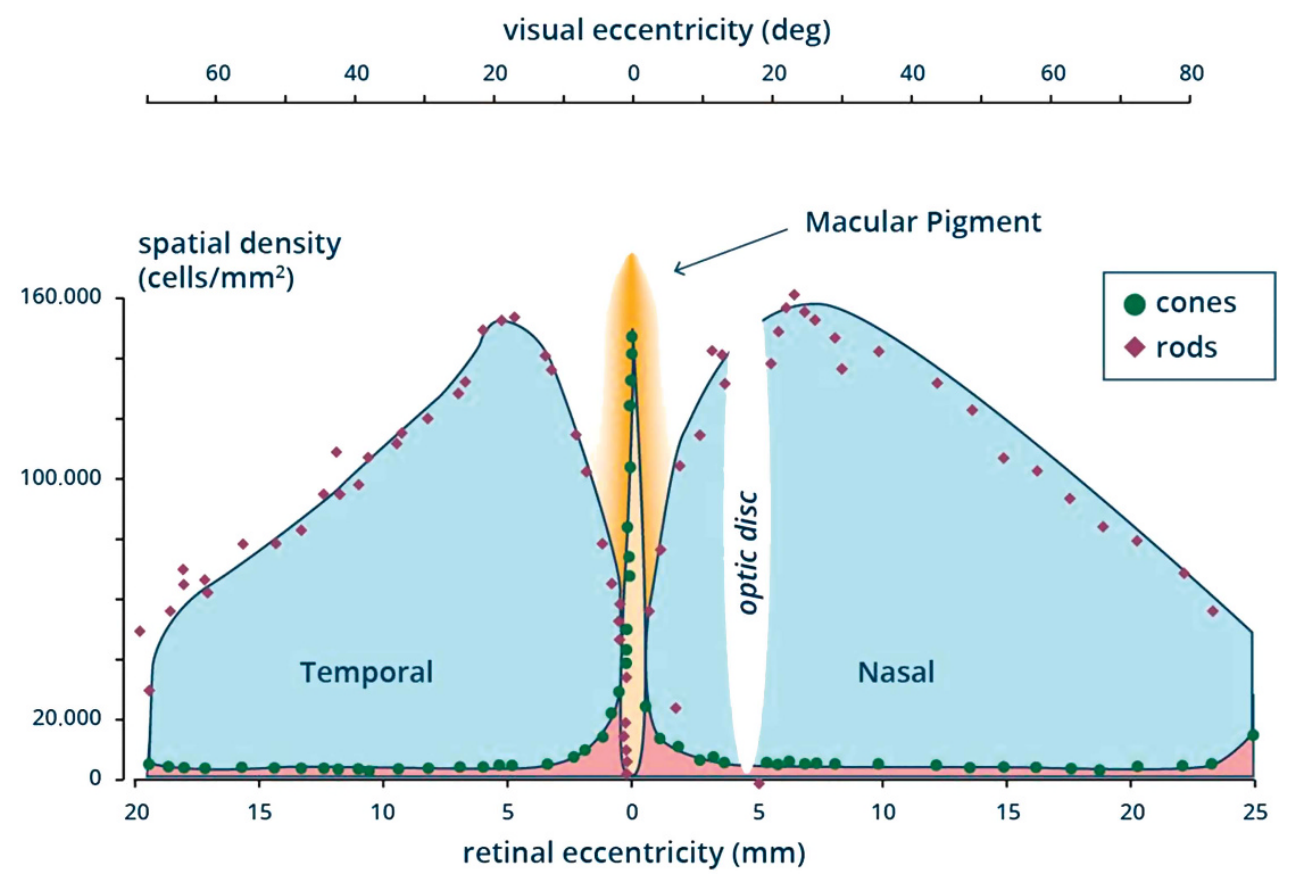

Figure 5 Illustration of distribution of the photoreceptors (cones and rods) across the retina.73,75 
blue light between 440 and $500 \mathrm{~nm}$, compared with only $6 \%$ of such wavelengths being filtered out by standard UV-only filtering IOLs, there is a real concern that IOLs that filter short-wavelength visible light selectively and adversely impact upon the ability to see in the dark. ${ }^{84}$ Theoretical calculations estimate that blue light-filtering IOLs reduce scotopic sensitivity by $14-21 \%$, depending on dioptric power. ${ }^{84,85}$

Commentators who have argued that the observed decrease in scotopic retinal sensitivity attributable to blue light-filtering IOLs is not clinically meaningful have premised their views on the fact that blue visible light represents only a small portion of the entire visible spectrum, ${ }^{86}$ and that such blue light-filtering IOLs show similar transmittance to a 75 -year-old lens. ${ }^{58}$ However, and given that the primary objective of cataract surgery is to restore pre-cataract vision and to prevent further agerelated decline in vision, it is difficult to argue in favour of replacing an aging, yellowing and cataractous lens with a manufactured IOL with similar absorbance characteristics, which cannot in any way alleviate the agerelated decline in scotopic vision that older adults find so disturbing. Indeed, it is reasonable to hypothesise that the ability to accumulate the macular carotenoids only in the central retina has evolved to optimize the quality of central vision by attenuating the adverse effects of (blue) light scatter and CA, whilst ensuring that the non-central retina is not deprived of visible short-wavelength light that is so important for vision under dim light. ${ }^{87}$

In other words, blue light-filtering IOLs necessarily filter blue light, which is responsible for 35\% of aphakic scotopic vision, and such IOLs may necessarily and adversely impact on vision under dim light conditions, but are unlikely to adversely impact on vision mediated (even in part) by cones (ie, photopic and mesopic vision), because the filtered visible wavelengths are responsible for only $7 \%$ of photopic vision. To test the hypothesis that vision mediated solely or partly by rods (ie, scotopic and mesopic vision, respectively) is adversely affected by implantation of blue light-filtering IOLs, vision needs to be tested in subjects with such IOLs $v$ s subjects with implanted standard UV-only filtering IOLs, but in a way that takes full account of the impact of another prereceptoral blue light filter (ie, MP) and to test mesopic and scotopic retinal sensitivity where there is no MP (ie, beyond $7^{\circ}$ eccentricity). Unfortunately, however, there is not a single study attempting to investigate the impact of blue light-filtering IOLs on central vision where MP was measured, and only a solitary study has measured scotopic retinal sensitivity in retina devoid of $\mathrm{MP}$, where it was confirmed that such IOLs did indeed adversely impact on rod-mediated retinal sensitivity. ${ }^{88}$

\section{Studies investigating mesopic/scotopic vision following implantation of blue-light-filtering IOLs}

The vision in darkness that is mediated solely by rods is known as scotopic vision. In one paper (evidence level 3b, Table 1), 22 patients with bilateral pseudophakia and early AMD were recruited to investigate whether a blue light-filtering IOL would affect vision-dependent tasks under scotopic conditions. ${ }^{89}$ These vision-dependent tasks, which included tests of eye-hand coordination and of mobility, were performed with and without blue-lightfiltering spectacles (worn in randomized order), and challenges included a mobility obstacle course, manipulation of cylindrical blocks and a psychophysical dark-adapted full-field flash test. Further, a navy ws blue sock color-sorting task was used to evaluate photopic color discrimination. Although performance of these tasks under scotopic conditions did not differ when patients attempted to conduct them with or without blue-lightfiltering spectacles, failure to discriminate between navy vs blue sock in the color-sorting task was significantly higher amongst those wearing blue-light-filtering spectacles $(P<0.001)$.

Greenstein et $a l^{88}$ reported another level $3 b$ study designed to investigate possible adverse effects of a bluelight-filtering IOL on scotopic sensitivity and hue discrimination under scotopic conditions. Nine patients with a blue light-filtering IOL (AcrySof SN60AT) in one eye and a UV-only filtering IOL (AcrySof SA60AT) in the fellow eye, as well as another nine young phakic patients (tested under conditions with a yellow-tinted clip-on lens and without such a lens) were recruited for the purposes of this study. Hue discrimination and dark-adapted thresholds to 440,500 , and $650 \mathrm{~nm}$ light were measured, and results suggested that, in the 9 operated patients, there were no significant differences in hue discrimination or dark-adapted sensitivity between fellow eyes. ${ }^{88}$ However, with the clip-on lens, mean sensitivities to the 440,500 , and $650 \mathrm{~nm}$ stimuli were significantly decreased by $2.7-2.8 \mathrm{~dB}, 0.7-1.0 \mathrm{~dB}$, and $0-1.2 \mathrm{~dB}$, respectively. ${ }^{88}$

Another level $3 \mathrm{~b}$ study designed to compare measures of photopic and scotopic CS in eyes with an AcrySof SN60AT Natural IOL (blue-light-filtering) and eyes with a conventional AcrySof SA60AT IOL (UV-only filtering) was reported, where the right eye of 38 patients was implanted with the former and right eye of 38 agematched controls with the latter. ${ }^{90}$ In brief, no statistically significant differences were observed between the two IOL types in terms of CS, scotopic CS or in terms of bluegreen color vision.

In the study (level 2 b) reported by Kara-Junior, ${ }^{91}$ where one eye of 60 subjects was implanted with a UV-only filtering IOL and the fellow eye implanted with a bluelight-filtering IOL, there was no difference between the 
two IOL types in terms of CS or color vision; further, a detailed examination, which included measurement of central retinal thickness by optical coherence tomography and a judgement on whether clinically significant macular change were apparent on slit-lamp biomicroscopy, was performed by a retinal specialist 5 years after surgery, and there was no difference between the two IOL types in this respect.

There is a weakness inherent in all studies that have attempted to investigate mesopic visual function following implantation of blue light-filtering IOLs, namely that all have utilized measures that are a function of only central vision, where MP is also acting as a blue light filter (but MP was not measured or corrected for in any of these studies). Further, of the four studies reporting on 'scotopic' vision in eyes following implantation with blue-light-filtering IOLs, ${ }^{88,90-92}$ two used luminance values $>1 \mathrm{~cd} / \mathrm{m}^{2}, 91,92$ thereby, in fact, reporting on mesopic vision that is mediated, at least in part, by cones, and therefore less likely to be adversely influenced by the transmittance properties of such blue-blocking IOLs.

\section{Blue-light-filtering IOLs and non-vision-forming perception}

In higher animals, photoreception can be classed as vision-forming and non-vision-forming, and in mammals the former is mediated by rods and cones, whereas the latter is mediated by the intrinsically photosensitive retinal ganglion cells (ipRGCs), which contain melanopsin. ${ }^{93}$ Indeed, the detection of irradiation by melanopsin stimulates photoentrainment of circadian rhythm via the retinohypothalamic tract, in a way that can convey non-vision-forming perception in the absence of functioning rods and cones (although the output of ipRGCs is normally regulated by input from these photoreceptors). ${ }^{94,95}$ The maintenance of photoentrainment of circadian rhythm in persons with no conscious perception of light is attributable to ipRGCs. ${ }^{96}$

It has been demonstrated that exposure to blue light can suppress melatonin secretion, thereby linking photoreception with sleep regulation. ${ }^{97,98}$ Indeed, Herljevic et al ${ }^{99}$ have shown significantly reduced melatonin suppression in elderly subjects following exposure to short-wavelength visible light $(456 \mathrm{~nm})$ compared with young subjects, and attributed their findings to the transmittance properties of cataracts. Melanopsin (a photosensitive pigment contained within ipRGCs) is maximally stimulated by blue light at $\sim 480 \mathrm{~nm}$, with significant absorption down to 420 $\mathrm{nm},{ }^{100,101}$ prompting concern that implantation of bluelight-filtering IOLs could contribute to sleep disorders. ${ }^{101}$ Some commentators have estimated that blue-lightfiltering IOLs are associated with $27-38 \%$ less melatonin suppression than standard UV-only filtering IOLs, although comparisons with a cataractous lens have not been made. ${ }^{14}$ Given that, in older individuals, the effective retinal light exposure is circa one-tenth that of younger individuals, ${ }^{102}$ and since cataract surgery can therefore be expected to greatly increase melatonin suppression, it is unlikely that implantation of a blue light-filtering IOL to replace a yellow cataract would have a disproportionate impact on circadian cycles. Indeed, this view is borne out by studies demonstrating improved sleep patterns following cataract surgery, in a way that is comparable for patients in whom blue-light-filtering IOLs were implanted vs those in whom standard UV-only IOLs were implanted. ${ }^{103,104}$

Ayaki et al ${ }^{105}$ reported a study (71 patients; mean (SD) age, $74.1( \pm 8.8))$ on the subject of sleep pattern following cataract surgery using UV-only filtering IOLs (evidence level 3b, Table 1), and concluded that implantation of an UV-only filtering IOL has potential for improving sleep quality and gait speed, in addition to restoring vision and vision-related quality of life. Indeed, improved sleep patterns have consistently been reported following cataract surgery where UV-only filtering IOLs were implanted at the time of procedure. ${ }^{106-108}$

In one cohort study (evidence level 4, Table 1), 206 patients undergoing cataract surgery with implantation of a UV-only filtering IOL (Acrysof SA60AT) or a blue lightfiltering IOL (Acrysof SN60WF) were recruited to make comparisons in terms of post-operative quality of life and sleep patterns. ${ }^{109}$ The outcome measures were evaluated using the National Eye Institute Visual Function Questionnaire (VFQ-25) and Pittsburgh Sleep Quality Index (PSQI) before surgery, and again 2 months and 7 months post-operatively. In brief, there were significant improvements in the sub-scale scores for sleep latency $(P<0.001$ at 7 months, unpaired $t$ test $)$ and sleep disturbance $(P<0.05$ and $P<0.01$ at 2 and 7 months, respectively) in patients implanted with a UV-only filtering IOL, but no such improvements were noted for eyes implanted with the blue-light-filtering IOL. ${ }^{109}$

A single center, double-masked, block-randomized clinical trial (evidence level 2b) involving one eye (the eye with lowest visual acuity) of 76 patients was reported to investigate the effect of cataract surgery on circadian photoentrainment, and to see if there was any difference between blue-light-filtering IOLs and UV-only filtering IOLs in this respect. ${ }^{110}$ The primary outcome measure was activation of intrinsic photosensitive ganglion cells (using post-illumination pupil response to blue light from 10 to $30 \mathrm{~s}$ after light exposure), which was measured 2 days and 3 weeks following the procedure. Secondary outcomes included circadian rhythm and measures of 24-h salivary melatonin, where sleep quality was determined by actigraphy and the Pittsburgh Sleep 
Quality Index. In brief, the authors observed no difference between patients who received blue light-filtering IOLs vs the UV-only filtering IOLs, but the authors conceded that the study was not designed to address the possible impact of cataract surgery on circadian photoentrainment or sleep in the longer term or following surgery in the second (fellow) eye. ${ }^{110}$

In one non-randomized study (evidence level 4, Table 1), 961 patients were implanted with either a UV-only filtering IOL $(n=498)$ or a blue light-filtering IOL $(n=463)$ at the time of cataract surgery. ${ }^{104}$ PSQI scores were recorded 1, 6, and 12 months following the surgery, and, in brief, overall sleep quality and sleep latency improved following the procedure, irrespective of the absorbance properties of the implanted IOLs (and there was no observed difference between the two IOLs). ${ }^{104}$

In another study (evidence level $2 b$, Table 1 ), 80 patients were randomised to receive either a UV-only filtering IOL (AMO Tecnis ZCB00) or a blue light-filtering IOL (Acrysof SN60WF) in at least one of two eyes. ${ }^{111}$ Outcome measures included reaction time (response to sensory stimulus) and the Epworth Sleepiness Score (ESS) questionnaire. It was found that cataract surgery (particularly first-eye surgery) had a beneficial effect in terms of cognition and daytime alertness, regardless of the absorbance properties of the implanted IOL (and there was no observed difference between the two types of IOL). ${ }^{111}$

A large-scale study was designed to investigate changes in blood pressure and sleep duration following cataract surgery with IOL implantation (various models, some blue light-filtering $(n=1059)$ and some not $(n=308))$, and to investigate how different types of IOL influence the degree of observed effects (evidence level 3b). ${ }^{112}$ Information relating to sleep duration (6 h or less, between 6.5 and $8 \mathrm{~h}$, or $8.5 \mathrm{~h}$ or more) were collected from 1367 patients (who were scheduled to and subsequently underwent cataract surgery in one eye) before surgery, 1 week after surgery and 1 month after surgery, and it was reported that sleep duration was improved following cataract surgery, irrespective of the types of IOL implanted at the time of the procedure. ${ }^{112}$

\section{Blue-light-filtering IOLs and phototoxicity}

Oxidative stress refers to tissue damage by unstable molecules, known as reactive oxygen intermediates (ROIs), and these compounds include free radicals, hydrogen peroxide, and singlet oxygen. ${ }^{113}$ The retina is especially susceptible to oxidative stress as it has the highest oxygen metabolism in the mammalian world, and because it is exposed to irradiation (ie, visible light), which is known to increase production of ROIs. Of the visible spectrum, high-energy short-wavelength visible light is the most injurious in terms of ROI production. ${ }^{113}$ Further, the retina is particularly vulnerable to damage by ROIs because of the high concentration of polyunsaturated fatty acids (PUFAs) in the outer segment membranes of the photoreceptors, as PUFAs contain readily accessible electrons in their double bonds. As a consequence, it has been hypothesized that oxidative stress and cumulative lifetime exposure to visible light are important factors in the pathogenesis of AMD, and this hypothesis is consistent with the proven benefits of antioxidant supplements in terms of retardation of disease progression. ${ }^{114,115}$

Valid studies designed to investigate the relative importance of retinal exposure to short-wavelength visible (blue) light following cataract surgery are unlikely to yield definitive results, as it would be impossible to control for the cumulative exposure to such visible wavelengths before surgery, which would be dependent on a plethora of variables including the age of the patient at the time of surgery, the duration and extent of the yellowing of the lens opacity, MPOD, amongst other factors. In other words, the hypothesized photoprotective benefits of implanting blue-light-filtering IOLs at the time of cataract surgery is unlikely to be either proven or refuted, and the surgeon must therefore elect to make a decision based on a rationale rather than on an evidence base. Of note, implantation of UV-only filtering IOLs at the time of cataract surgery in 1167 of 4577 AREDS participants with intermediate age-related macular degeneration (AMD), in the context of 6 monthly retinal reviews and follow-up of at least 5 years, was not associated with progression to advanced AMD. ${ }^{116}$

A 2-year prospective observational study (evidence level 4, Table 1) was reported by Nagai et al ${ }^{117}$, and was designed to evaluate changes in fundus autofluorescence in the 2 years following implantation of blue-lightfiltering IOLs (YA-60BBR, Hoya Corp.) vs UV-only filtering IOLs (VA-60BBR, Hoya Corp.) at the time of cataract surgery. Abnormal fundus autofluorescence has been recognized as predictive of development of geographic atrophy and neovascular AMD. ${ }^{118,119}$ The study consisted of 52 eyes of 52 patients where a bluelight-filtering IOL was implanted and 79 eyes of 79 patients where a UV-only filtering IOL was implanted, and outcomes included changes in fundus autofluorescence and evidence of AMD development and, in particular, geographic atrophy. In this study, increased fundus autofluorescence was seen in the UV-only filtering IOL group only, suggesting that the blue-light-filtering IOL might protect against AMD. The limitations of this study include its small number of subjects and its design. A comparative randomized study with more patients and a longer period of follow-up is required to investigate 
whether or not blue light-filtering IOLs are protective against AMD development. Another criticism of this paper rests on the fact that it is very likely that the measures of autofluorescence are influenced by the absorbance properties of the preoperative cataract and of the implanted $\mathrm{IOL}^{120}$ and, accordingly, the severity and grade of the preoperative lens opacity and the impact of the IOL's absorbance properties on measurements should be factored into analysis.

In another study, representing evidence level $3 b$ (Table 1), the impact of the filtration properties of the implanted IOL on progression of geographic atrophy was assessed, where 66 eyes of 40 patients afflicted with AMD were implanted with either a blue light-filtering IOL $(n=27$; AcrySof SN60WF) or a UV-only filtering IOL ( $n=39$; various models), and followed for a period of 1 year following surgery. ${ }^{121}$ The primary outcome measure was progression of geographic atrophy, and the data suggested a protective effect in association with implantation of blue-light-filtering IOLs. ${ }^{121}$ However, it should be noted that there are many variables affecting rates of progression of atrophic AMD, including age and genetic background, and these were not factored into the analysis; $^{122-124}$ further, it is very likely that measures of autofluorescence are profoundly influenced by the nature and density of the cataract before surgery (not reported in this study) and by the absorbance properties of the IOL, thus confounding pre and post-operative measures of autofluorescence and negating any meaningful discussion.

\section{A comment on violet-blocking iols}

The term 'violet-blocking' IOL has been coined to describe IOLs that block wavelengths between 400 and $440 \mathrm{~nm}$ but do not block wavelengths $>440 \mathrm{~nm},{ }^{14}$ and such IOLs have been introduced in an attempt to limit the disadvantages inherent in depriving the non-central retina of wavelengths between 440 and $500 \mathrm{~nm}$. However, and to our knowledge, there have been no studies comparing violet-blocking IOLs with blue-blocking IOLs in terms of vision-forming or non-vision-forming outcomes, or in terms of photoprotection.

\section{Conclusion}

In terms of photoprotection, there is no level $2 \mathrm{~b}$ (or higher) evidence in support of using blue light-filtering IOLs vs UV-only filtering IOLs at the time of cataract surgery. In general, the quality of evidence informing the surgeon's selection of IOLs on the basis of light transmittance properties is deficient.

\section{Method of literature search}

References for this review were identified through a retrospective literature search of the electronic PubMed database (2000-2016), and included where appropriate. The following key words and combination of these words were used in compiling the search: blue blocker, blue light-filtering, lens, AcrySof Natural, SN60AT and YA60BB. We included all studies involving patients (both male and female, above 16 years of age) undergoing cataract surgery and implantation of blue lightfiltering IOLs.

\section{Conflict of interest}

Professor John M Nolan and Professor Stephen Beatty do consultancy work for nutraceutical companies, in a personal capacity, and are directors of Nutrasight Consultancy Limited. The remaining authors declare no conflict of interest.

\section{Acknowledgements}

Jessica Dennison and John Nolan are funded by the European Research Council grant 281096.

\section{References}

1 Allen D, Vasavada A. Cataract and surgery for cataract. BMJ 2006; 333: 128-132.

2 Etzioni DA, Liu JH, Maggard MA, Ko CY. The aging population and its impact on the surgery workforce. Ann Surg 2003; 238: 170-177.

3 Hayashi K, Hayashi H, Nakao F, Hayashi F. Changes in posterior capsule opacification after poly(methyl methacrylate), silicone, and acrylic intraocular lens implantation. J Cataract Refract Surg 2001; 27: 817-824.

4 Hayashi H, Hayashi K, Nakao F, Hayashi F. Quantitative comparison of posterior capsule opacification after polymethylmethacrylate, silicone, and soft acrylic intraocular lens implantation. Arch Ophthalmol 1998; 116: 1579-1582.

5 van der Linden JW, van der Meulen IJ, Mourits MP, Lapid-Gortzak R. Comparison of a hydrophilic and a hydrophobic apodized diffractive multifocal intraocular lens. Int Ophthalmol 2013; 33: 493-500.

6 Koch DD, Wang L. Custom optimization of intraocular lens asphericity. Trans Am Ophthalmol Soc 2007; 105: 36-41.

7 Edwards KH, Gibson GA. Intraocular lens short wavelength light filtering. Clin Exp Optom 2010; 93: 390-399.

8 Margrain TH, Boulton M, Marshall J, Sliney DH. Do blue light filters confer protection against age-related macular degeneration? Prog Retin Eye Res. 2004; 23: 523-531.

9 Boettner E, Wolter J. Transmission of the ocular media. Invest Ophthalmol Vis Sci 1962; 1: 776-783.

10 Lavric A, Pompe MT. Do blue-light filtering intraocular lenses affect visual function? Optom Vis Sci 2014; 91(11): 1348-1354. 
11 Bron AJ, Vrensen GF, Koretz J, Maraini G, Harding JJ. The ageing lens. Ophthalmologica 2000; 214: 86-104.

12 Miller RE, Tredici TJ. Night Vision Manual for the Flight Surgeon. In. AL-SR-1992-0002 ed. 1992.

13 Mainster MA. Intraocular lenses should block UV radiation and violet but not blue light. Arch Ophthalmol 2005; 123: 550-555.

14 Mainster MA. Violet and blue light blocking intraocular lenses: photoprotection vs photoreception. $\mathrm{Br} J$ Ophthalmol 2006; 90: 784-792.

15 Provis JM, Penfold PL, Cornish EE, Sandercoe TM, Madigan MC. Anatomy and development of the macula: specialisation and the vulnerability to macular degeneration. Clin Exp Optom 2005; 88: 269-281.

16 Engel S, Zhang X, Wandell B. Colour tuning in human visual cortex measured with functional magnetic resonance imaging. Nature 1997; 388: 68-71.

17 Bowmaker JK, Dartnall HJ. Visual pigments of rods and cones in a human retina. J Physiol 1980; 298: 501-511.

18 Stringham NT, Sabatinelli D, Stringham JM. A potential mechanism for compensation in the blue-yellow visual channel. Front Hum Neurosci 2013; 7: 331.

19 Stringham JM, Hammond BR Jr. Compensation for light loss due to filtering by macular pigment: relation to hue cancellation. Ophthalmic Physiol Opt 2007; 27: 232-237.

20 Stringham JM, Hammond BR, Wooten BR, Snodderly DM. Compensation for light loss resulting from filtering by macular pigment: relation to the S-cone pathway. Optom Vis Sci 2006; 83: 887-894.

21 Howarth PA, Bradley A. The longitudinal chromatic aberration of the human eye, and its correction. Vision Res 1986; 26: 361-366.

22 Yang SN, Tai YC, Laukkanen H, Sheedy J. Effects of ocular transverse chromatic aberration on near foveal letter recognition. Vision Res 2009; 49: 2881-2890.

23 Chang J, Kang H, Kang MG. Correction of axial and lateral chromatic aberration with false color filtering. IEEE Trans Image Process 2013; 22: 1186-1198.

24 Thibos LN, Bradley A, Zhang XX. Effect of ocular chromatic aberration on monocular visual performance. Optom Vis Sci 1991; 68: 599-607.

25 Campbell FW, Gubisch RW. The effect of chromatic aberration on visual acuity. J Physiol 1967; 192: 345-358.

26 Reading VM, Weale RA. Macular pigment and chromatic aberration. J Opt Soc Am 1974; 64: 231-234.

27 McLellan JS, Marcos S, Prieto PM, Burns SA. Imperfect optics may be the eye's defence against chromatic blur. Nature 2002; 417: 174-176.

28 Vos JJ, Boogaard J. Contribution of the cornea to entoptic scatter. J Opt Soc Am 1963; 53: 869-873.

29 Vos JJ. On the cause of disability glare and its dependence on glare angle, age and ocular pigmentation. Clin Exp Optom 2003; 86: 363-370.

30 Wooten BR, Geri GA. Psychophysical determination of intraocular light scatter as a function of wavelength. Vision Res 1987; 27: 1291-1298.

31 Demott DW, Davis TP. Entoptic scatter as a function of wavelength. J Opt Soc Am 1960; 50: 495-496.

32 Wooten BR, Hammond BR. Macular pigment: influences on visual acuity and visibility. Prog Retin Eye Res 2002; 21: 225-240.

33 Costello MJ, Johnsen S, Gilliland KO, Freel CD, Fowler WC. Predicted light scattering from particles observed in human age-related nuclear cataracts using mie scattering theory. Invest Ophthalmol Vis Sci 2007; 48: 303-312.

34 Hammond BR Jr, Fletcher LM. Influence of the dietary carotenoids lutein and zeaxanthin on visual performance: application to baseball. Am J Clin Nutr 2012; 96: 1207S-1213S.

35 Issolio LA, Barrionuevo PA, Comastri SA, Colombo EM. Veiling luminance as a descriptor of brightness reduction caused by transient glare. J Opt Soc Am A Opt Image Sci Vis 2012; 29: 2230-2236.

36 Mainster MA, Turner PL. Glare's causes, consequences, and clinical challenges after a century of ophthalmic study. Am J Ophthalmol 2012; 153: 587-593.

37 Vos JJ. Reflections on glare. Light Res Technol 2003; 35: 163-176.

38 Williams DR, MacLeod DI, Hayhoe MM. Punctate sensitivity of the blue-sensitive mechanism. Vision Res 1981; 21: 1357-1375.

39 Ahnelt PK, Kolb H. The mammalian photoreceptor mosaicadaptive design. Prog Retin Eye Res 2000; 19: 711-777.

40 Wald G. Human vision and the spectrum. Science 1945; 101: 653-658.

41 Snodderly DM, Auran JD, Delori FC. The macular pigment. II. Spatial distribution in primate retinas. Invest Ophthalmol Visual Sci 1984; 25: 674-685.

42 Sabour-Pickett S, Beatty S, Connolly E, Loughman J, Stack J, Howard A et al. Supplementation with three different macular carotenoid formulations in patients with early agerelated macular degeneration. Retina 2014; 34: 1757-1766.

43 Richer S, Stiles W, Statkute L, Pulido J, Frankowski J, Rudy D et al. Double-masked, placebo-controlled, randomized trial of lutein and antioxidant supplementation in the intervention of atrophic age-related macular degeneration: the Veterans LAST study (Lutein Antioxidant Supplementation Trial). Optometry 2004; 75: 216-230.

44 Richer SP, Stiles W, Graham-Hoffman K, Levin M, Ruskin D, Wrobel J et al. Randomized, double-blind, placebo-controlled study of zeaxanthin and visual function in patients with atrophic age-related macular degeneration: the Zeaxanthin and Visual Function Study (ZVF) FDA IND \#78, 973. Optometry 2011; 82: 667-680.

45 Sasamoto Y, Gomi F, Sawa M, Tsujikawa M, Nishida K. Effect of 1-year lutein supplementation on macular pigment optical density and visual function. Graefes Arch Clin Exp Ophthalmol 2011; 249: 1847-1854.

46 Loughman J, Nolan JM, Howard AN, Connolly E, Meagher K, Beatty S. The impact of macular pigment augmentation on visual performance using different carotenoid formulations. Invest Ophthalmol Vis Sci 2012; 53: 7871-7880.

47 Loughman J, Akkali MC, Beatty S, Scanlon G, Davison PA, O'Dwyer $\mathrm{V}$ et al. The relationship between macular pigment and visual performance. Vision Res 2010; 50: 1249-1256.

48 Nolan JM, Loughman J, Akkali MC, Stack J, Scanlon G, Davison $\mathrm{P}$ et al. The impact of macular pigment augmentation on visual performance in normal subjects: COMPASS. Vision Res 2011; 51(5): 459-469.

49 Hammond Jr BR, Wooten BR, Engles M, Wong JC. The influence of filtering by the macular carotenoids on contrast sensitivity measured under simulated blue haze conditions. Vision Res 2012; 63: 58-62.

50 Hammond BR Jr, Fletcher LM, Elliott JG. Glare disability, photostress recovery, and chromatic contrast: relation to 
macular pigment and serum lutein and zeaxanthin. Invest Ophthalmol Vis Sci 2013; 54: 476-481.

51 Kvansakul J, Rodriguez-Carmona M, Edgar DF, Barker FM, Köpcke W, Schalch $\mathrm{W}$ et al. Supplementation with the carotenoids lutein or zeaxanthin improves human visual performance. Ophthalmic Physiol Opt 2006; 26: 362-371.

52 Stringham JM, Hammond BR. Macular pigment and visual performance under glare conditions. Optom Vis Sci 2008; 85: $82-88$.

53 Ma L, Lin XM, Zou ZY, Xu XR, Li Y, Xu R. A 12-week lutein supplementation improves visual function in Chinese people with long-term computer display light exposure. Br J Nutr 2009; 102: 186-190.

54 Hammond BR, Wooten BR, Snodderly DM. Individual variations in the spatial profile of human macular pigment. J Opt Soc Am A Opt Image Sci Vis 1997; 14: 1187-1196.

55 Nolan JM, Power R, Stringham J, Dennison J, Stack J, Kelly D et al. Enrichment of macular pigment enhances contrast sensitivity in subjects free of retinal disease: Central Retinal Enrichment Supplementation TrialsReport1. Invest Ophthalmol Vis Sci 2016; 57(7): 3429-3439.

56 Mellerio J. Yellowing of the human lens: nuclear and cortical contributions. Vision Res 1987; 27: 1581-1587.

57 Dillon J, Atherton SJ. Time resolved spectroscopic studies on the intact human lens. Photochem Photobiol 1990; 51: $465-468$.

58 Henderson BA, Grimes KJ. Blue-blocking IOLs: a complete review of the literature. Surv Ophthalmol 2010; 55: 284-289.

59 Mainster MA. Spectral transmittance of intraocular lenses and retinal damage from intense light sources. $A m \mathrm{~J}$ Ophthalmol 1978; 85: 167-170.

60 Mainster MA. Solar retinitis, photic maculopathy and the pseudophakic eye. J Am Intraocul Implant Soc 1978; 4: 84-86.

61 Mainster MA. The spectra, classification, and rationale of ultraviolet-protective intraocular lenses. Am J Ophthalmol 1986; 102: 727-732.

62 Alcon Laboratories. Product Information: AcrySof Natural Single-Piece IOL, In: Alcon Laboratories, Inc.: Fort Worth, TX, USA, 2013.

63 Hammond BR, Antonio B. Attenuating photostress and glare disability in pseudophakic patients through the addition of a short-wave absorbing filter. J. Ophthalmol 2015; 2015: 607635.

64 Landers J, Tan TH, Yuen J, Liu H. Comparison of visual function following implantation of Acrysof Natural intraocular lenses with conventional intraocular lenses. Clin Experiment Ophthalmol 2007; 35: 152-159.

65 Miyata A. Neutralization method for detecting the incidence of color perception changes after cataract surgery. J Cataract Refract Surg 2015; 41(4): 764-770.

66 Yuan Z, Reinach P, Yuan J. Contrast sensitivity and color vision with a yellow intraocular len. Am J Ophthalmol 2004; 138: 138-140.

67 Bandyopadhyay S, Saha M, Chakrabarti A, Sinha A. Effect on contrast sensitivity after clear, yellow and orange intraocular lens implantation. Int Ophthalmol 2016; 36(3): 313-318.

68 Akuffo KO, Beatty S, Stack J, Dennison J, O'Regan S, Meagher KA et al. Central retinal enrichment supplementation trials (CREST): design and methodology of the CREST randomized controlled trials. Ophthalmic Epidemiol 2014; 21(2): 111-123.
69 Wyszecki G, Blevin W, Kessler K, Mielenz K. Principles governing photometry. Monographie BIPM. Luisant: Imprimerie Durand: 1983.

70 Berg J, Tymoczko J, Stryer L. Sensory systems. Biochemistry, 5th edn. WH Freeman: New York, NY, USA, 2002.

71 Crescitelli F, Dartnall HJ. Human visual purple. Nature 1953; 172: 195-197.

72 Rushton WA. The difference spectrum and the photosensitivity of rhodopsin in the living human eye. J Physiol 1956; 134: 11-29.

73 Purve D, Augustine GJ, Fitzpatrick D, Katz LC, LaMantia AS, McNamara JO et al. Neuroscience, 2nd edn. Sinauer Associates: Sunderland, MA, USA, 2001.

74 Curcio CA, Sloan KR, Kalina RE, Hendrickson AE. Human photoreceptor topography. J Comp Neurol 1990; 292: 497-523.

75 Shevell SK. The Science of Color, 2nd edn. Elvsevier: Amsterdam, 2003.

76 Jackson GR, Owsley C. Scotopic sensitivity during adulthood. Vision Res 2000; 40: 2467-2473.

77 Curcio CA, Millican CL, Allen KA, Kalina RE. Aging of the human photoreceptor mosaic: evidence for selective vulnerability of rods in central retina. Invest Ophthalmol Vis Sci 1993; 34: 3278-3296.

78 Pitts DG. Dark adaptation and aging. J Am Optom Assoc 1982; 53: 37-41.

79 Schefrin BE, Tregear SJ, Harvey LO Jr, Werner JS. Senescent changes in scotopic contrast sensitivity. Vision Res 1999; 39: 3728-3736.

80 Jackson GR, Owsley C, McGwin G Jr. Aging and dark adaptation. Vision Res 1999; 39: 3975-3982.

81 Sturr JF, Zhang L, Taub HA et al. Psychophysical evidence for losses in rod sensitivity in the aging visual system. Vision Res 1997; 37: 475-481.

82 McMurdo ME, Gaskell A. Dark adaptation and falls in the elderly. Gerontology 1991; 37: 221-224.

83 Sivak M, Olson PL, Pastalan LA. Effect of driver's age on nighttime legibility of highway signs. Hum Factors 1981; 23: 59-64.

84 Mainster MA, Sparrow JR. How much blue light should an IOL transmit? Br J Ophthalmol 2003; 87: 1523-1529.

85 Schwiegerling J. Blue-light-absorbing lenses and their effect on scotopic vision. J Cataract Refract Surg 2006; 32: 141-144.

86 Werner JS. Night vision in the elderly: consequences for seeing through a 'blue filtering' intraocular lens. $\mathrm{Br} J$ Ophthalmol 2005; 89: 1518-1521.

87 Bone RA, Landrum JT, Fernandez L, Tarsis SL. Analysis of the macular pigment by HPLC: retinal distribution and age study. Invest Ophthalmol Visual Sci 1988; 29: 843-849.

88 Greenstein VC, Chiosi F, Baker P, Seiple W, Holopigian K, Braunstein RE et al. Scotopic sensitivity and color vision with a blue-light-absorbing intraocular lens. J Cataract Refract Surg 2007; 33: 667-672.

89 Kiser AK, Deschler EK, Dagnelie G. Visual function and performance with blue-light blocking filters in age-related macular degeneration. Clin Experiment Ophthalmol 2008; 36 (6): 514-520.

90 Muftuoglu O, Karel F, Duman R. Effect of a yellow intraocular lens on scotopic vision, glare disability, and blue color perception. J Cataract Refract Surg 2007; 33: 658-666.

91 Schmack I, Schimpf M, Stolzenberg A, Conrad-Hengerer I, Hengerer FH, Dick HB. Visual quality assessment in patients with orange-tinted blue light-filtering and clear 
ultraviolet light-filtering intraocular lenses. J Cataract Refract Surg 2012; 38: 823-832.

92 Kara-Junior N, Espindola RF, Gomes BA, Ventura B, Smadja D, Santhiago MR. Effects of blue light-filtering intraocular lenses on the macula, contrast sensitivity, and color vision after a long-term follow-up. J Cataract Refract Surg 2011; 37: 2115-2119.

93 Hankins MW, Peirson SN, Foster RG. Melanopsin: an exciting photopigment. Trends Neurosci 2008; 31: 27-36.

94 Freedman MS, Lucas RJ, Soni B, von Schantz M, Muñoz M, David-Gray $\mathrm{Z}$ et al. Regulation of mammalian circadian behavior by non-rod, non-cone, ocular photoreceptors. Science 1999; 284: 502-504.

95 Dollet A, Albrecht U, Cooper HM, Dkhissi-Benyahya O. Cones are required for normal temporal responses to light of phase shifts and clock gene expression. Chronobiol Int 2010; 27: 768-781.

96 Sack RL, Lewy AJ, Blood ML, Keith LD, Nakagawa H. Circadian rhythm abnormalities in totally blind people: incidence and clinical significance. J Clin Endocrinol Metab 1992; 75: 127-134.

97 Lewy AJ, Wehr TA, Goodwin FK, Newsome DA, Markey SP. Light suppresses melatonin secretion in humans. Science 1980; 210: 1267-1269.

98 Thapan K, Arendt J, Skene DJ. An action spectrum for melatonin suppression: evidence for a novel non-rod, non-cone photoreceptor system in humans. J Physiol 2001; 535: 261-267.

99 Herljevic M, Middleton B, Thapan K, Skene DJ. Lightinduced melatonin suppression: age-related reduction in response to short wavelength light. Exp Gerontol 2005; 40: 237-242.

100 Lucas RJ, Douglas RH, Foster RG. Characterization of an ocular photopigment capable of driving pupillary constriction in mice. Nat Neurosci 2001; 4: 621-626.

101 Turner PL, Mainster MA. Circadian photoreception: ageing and the eye's important role in systemic health. Br J Ophthalmol 2008; 92: 1439-1444.

102 Charman WN. Age, lens transmittance, and the possible effects of light on melatonin suppression. Ophthalmic Physiol Opt 2003; 23: 181-187.

103 Landers JA, Tamblyn D, Perriam D. Effect of a blue-lightblocking intraocular lens on the quality of sleep. J Cataract Refract Surg 2009; 35: 83-88.

104 Alexander I, Cuthbertson FM, Ratnarajan G, Safa R, Mellington FE, Foster RG et al. Impact of cataract surgery on sleep in patients receiving either ultra-violet blocking or blue-filtering intraocular lens implants. Invest Ophthalmol Vis Sci 2014; 55: 4999-5004.

105 Ayaki M, Negishi K, Tsubota K. Rejuvenation effects of cataract surgery with ultraviolet blocking intra-ocular lens on circadian rhythm and gait speed. Rejuvenation Res 2014; 17(4): 359-365.

106 Asplund R, Lindblad BE. The development of sleep in persons undergoing cataract surgery. Arch Gerontol Geriatr 2002; 35: 179-187.

107 Asplund R, Lindblad BE. Sleep and sleepiness 1 and 9 months after cataract surgery. Arch Gerontol Geriatr 2004; 38: 69-75.

108 Davison JA, Patel AS, Cunha JP, Schwiegerling J, Muftuoglu O. Recent studies provide an updated clinical perspective on blue light-filtering IOLs. Graefes Arch Clin Exp Ophthalmol 2011; 249: 957-968.
109 Ayaki M, Negishi K, Suzukamo Y, Tsubota K. Color of intra-ocular lens and cataract type are prognostic determinants of health indices after visual and photoreceptive restoration by surgery. Rejuvenation Res 2015; 18(2): 145-152.

110 Brøndsted AE, Sander B, Haargaard B, Lund-Andersen H, Jennum P, Gammeltoft $S$ et al. The Effect of cataract surgery on circadian photoentrainment: a randomized trial of blue-blocking $v s$ neutral intraocular lenses. Ophthalmology 2015; 122(10): 2115-2124.

111 Schmoll C, Khan A, Aspinall P, Goudie C, Koay P, Tendo $C$ et al. New light for old eyes: comparing melanopsin-mediated non-visual benefits of blue-light and UV-blocking intraocular lenses. Br J Ophthalmol 2014; 98(1): 124-128.

112 Ichikawa K, Hoshino M, Kato M, Kojima K, Kojima T, Naito $\mathrm{N}$ et al. Changes in blood pressure and sleep duration in patients with blue light-blocking/yellow-tinted intraocular lens (CHUKYO study). Hypertens Res 2014; 37 (7): 659-664.

113 Beatty S, Koh HH, Henson D, Boulton M. The role of oxidative stress in the pathogenesis of age-related macular degeneration. Surv Ophthalmol 2000; 45: 115-134.

114 SanGiovanni JP, Chew EY, Ferris FL, Kurinij N, Sperduto RD, Lindblad AS et al. Dietary carotenoids and risk for age-related macular degeneration in the AgeRelated Eye Disease Study (AREDS). Invest Ophthalmol Vis Sci 2004; 45: 2242.

115 Age-Related Eye disease Study Research Group. Lutein + zeaxanthin and omega-3 fatty acids for age-related macular degeneration: the Age-Related Eye Disease Study 2 (AREDS2) randomized clinical trial. JAMA 2013; 309: 2005-2015.

116 Chew EY, Sperduto RD, Milton RC, Clemons TE, Gensler GR, Bressler SB et al. Risk of advanced age-related macular degeneration after cataract surgery in the Age-Related Eye Disease Study: AREDS report 25. Ophthalmology 2009; 116: 297-303.

117 Nagai H, Hirano Y, Yasukawa T, Morita H, Nozaki M, Wolf-Schnurrbusch $U$ et al. Prevention of increased abnormal fundus autofluorescence with blue light-filtering intraocular lenses. J Cataract Refract Surg 2015; 41(9): 1855-1859.

118 Einbock W, Moessner A, Schnurrbusch UE, Holz FG, Wolf S. Changes in fundus autofluorescence in patients with age-related maculopathy. Correlation to visual function: a prospective study. Graefes Arch Clin Exp Ophthalmol 2005; 243: 300-305.

119 Holz FG, Bellmann C, Margaritidis M, Schutt F, Otto TP, Volcker HE. Patterns of increased in vivo fundus autofluorescence in the junction zone of geographic atrophy of the retinal pigment epithelium associated with agerelated macular degeneration. Graefes Arch Clin Exp Ophthalmol 1999; 237: 145-152.

120 Akuffo KO, Nolan JM, Stack J, Power R, Kirwan C, Moran $\mathrm{R}$ et al. The impact of cataract, and its surgical removal, on measures of macular pigment using the heidelberg spectralis HRA+OCT multicolor device. Invest Ophthalmol Vis Sci 2016; 57(6): 2552-2563.

121 Pipis A, Touliou E, Pillunat LE, Augustin AJ. Effect of the blue filter intraocular lens on the progression of geographic atrophy. Eur J Ophthalmol 2015; 25(2): 128-133.

122 Merle BM, Silver RE, Rosner B, Seddon JM. Dietary folate, B vitamins, genetic susceptibility and progression to 
advanced nonexudative age-related macular degeneration with geographic atrophy: a prospective cohort study. Am J Clin Nutr 2016; 103(4): 1135-1144.

123 Jonasson F, Fisher DE, Eiriksdottir G, Sigurdsson S, Klein R, Launer LJ et al. Five-year incidence, progression, and risk factors for age-related macular degeneration: the age, gene/ environment susceptibility study. Ophthalmology 2014; 121 (9): 1766-1772.

124 Seddon JM, Reynolds R, Yu Y, Rosner B. Three new genetic loci (R1210C in CFH, variants in COL8A1 and RAD51B) are independently related to progression to advanced macular degeneration. PLoS One 2014; 9(1): e87047.
This work is licensed under a Creative Commons Attribution 4.0 International License. The images or other third party material in this article are included in the article's Creative Commons license, unless indicated otherwise in the credit line; if the material is not included under the Creative Commons license, users will need to obtain permission from the license holder to reproduce the material. To view a copy of this license, visit http://creativecommons.org/licenses/by/4.0/

(C) The Author(s) 2017 